\title{
Radiochemical analysis of a copper beam dump irradiated with high-energetic protons
}

\author{
By D. Schumann ${ }^{1, *}$, J. Neuhausen ${ }^{1}$, J. Eikenberg ${ }^{1}$, M. Rüthi ${ }^{1}$, M. Wohlmuther ${ }^{1}$, P. W. Kubik ${ }^{2}$, H.-A. Synal ${ }^{2}$, V. Alfimov ${ }^{2}$, \\ G. Korschinek ${ }^{3}$, G. Rugel ${ }^{3}$ and Th. Faestermann ${ }^{3}$
}

\footnotetext{
${ }^{1}$ Paul Scherrer Institute Villigen, 5232 Villigen PSI, Switzerland

2 Laboratory for Ion Beam Physics, ETH Zurich, 8093 Zurich, Switzerland

${ }^{3}$ Technische Universität München, 85747 Garching, Germany
}

(Received June 20, 2008; accepted in revised form September 20, 2008)

\section{Radiochemical separation / LSC / AMS / Accelerator waste}

Summary. The radionuclide inventory of a copper beam dump from the $590 \mathrm{MeV}$ proton accelerator of the Paul Scherrer Institute in Switzerland was determined, focusing on radioisotopes with half-lives of more than $60 \mathrm{~d}$, and in particular, of long-lived isotopes with $T_{1 / 2}=10^{4}-10^{7}$ years, which are important regarding radioactive waste management. The measurements were carried out using high resolution $\gamma$-measurement without sample destruction, as well as liquid scintillation counting (LSC) and accelerator mass spectrometry (AMS) after chemical separation. For the first time, a beam dump from a high power accelerator facility was completely characterized concerning the depth and radial distribution profile of the most hazardous and/or long-lived radionuclides. Moreover, it turned out that some of the investigated radionuclides, like for instance ${ }^{26} \mathrm{Al},{ }^{44} \mathrm{Ti}$ or ${ }^{60} \mathrm{Fe}$ represent valuable material for application in several scientific fields like nuclear astrophysics, basic nuclear physics research, radiopharmacy and many others. Therefore, based on the analytical results, a special research and development program has been started at PSI objecting on specific preparative extraction of longlived radioisotopes (ERAWAST - exotic radionuclides from accelerator waste for science and technology).

\section{Introduction}

In the past, for the management of nuclear waste, the activated material produced by accelerator facilities did not play an important role. This was mainly caused both by the marginal volume of accumulated material and its relatively low content of radionuclides. However, with the development of new, large-scale facilities for several scientific purposes like spallation neutron sources (e.g. SNS in Oakridge, USA [1], SINQ-PSI [2] in Switzerland), radioactive beam facilities (RIB) already now existing (for instance SPIRAL at GANIL [3], UCL [4]), or planned to be build in the future (EURISOL design study [5]), new energy production and waste management concepts such as accelerator driven systems (ADS) [6] as well as the operation of accelerators for medical application (proton and heavy ion therapy [7],

\footnotetext{
*Author for correspondence (E-mail: dorothea.schumann@psi.ch).
}

positron emission tomography (PET) [8]), the characterization of accelerator waste with respect to an intermediate or final disposal is more and more spotlighted. Different from the treatment of waste from nuclear power plants (NPP), where the radionuclide inventory is well-known, the situation in the case of activated material from a cyclotron or a linear accelerator (LINAC) is much more complicated regarding the composition of the radwaste inventory. The residue nuclide production in material of such a facility depends strongly on the accelerated particles (e.g. protons, deuterons, $\alpha$-particles, and heavy ions), their energy and intensity, and, additionally on the properties of the secondarily induced particles (neutrons, protons, electrons, heavy fragments) and their nuclear reactions with the surrounding material. Especially in cases, where high-energetic protons are used, the spectrum of nuclear reactions taking place practically simultaneously is highly complex as is also the resulting spectrum of the produced radionuclides.

Modeling of the nuclear reactions in such systems in order to come to theoretical predictions for the expected radionuclide inventory had been forced within the recent years (see [9] and references therein), with the result that nowadays calculation codes are available for selected targetprojectile combinations in several energy ranges. However, the development of calculation codes is an iterative process requiring considerable amounts of data sets for the improvement of the modeling. As a consequence of the complexity of the subject and due to the extremely high variety of possible target-projectile combinations up to now for an assessment of the radionuclide inventory, one is up to now still far away from relying on theoretical predictions only. Quite the contrary, licensing authorities require extended analyzes for the disposal of accelerator waste. In this regard, radionuclides with high-energetic $\gamma$-radiation, $\alpha$-emitters as well as long-lived $\beta$-decaying radionuclides are especially considered owing to their potential risk for environmental pollution and dose to man, whereas isotopes with extremely long half-life are in a particular focus because of their impact on the long-term storage. In this context, also chemical and physico-chemical properties of these radio-elements (e.g. solubility, volatility, mobility) are of high importance, because they determine the evaluation of the environmental 
impact, and, in this way, influence the maximum permissible values.

The Paul Scherrer Institute (PSI) in Switzerland operates the most powerful proton accelerator world-wide - the $590-\mathrm{MeV}$ ring cyclotron with currently a beam intensity of $1.8 \mathrm{~mA}$ and a envisaged upgrade to $2.5 \mathrm{~mA}$. Targets, beam dumps, shielding as well as other components in the surrounding of this facility are highly activated and require accurate examination concerning dose rate and radionuclide inventory. The Swiss authority for the disposal of nuclear waste (NAGRA) issued nuclide-specific declaration limits (DL) for the activity content of accelerator waste from PSI, which is based on the permitted limits of the Swiss Radiation Protection Ordinance [10]. Moreover, so-called "permissible activity concentrations" (german: Zulässige Aktivitätskonzentration - ZAK) were defined, which shall give support for the validation of the risk potential of a radionuclides in a final disposal [11]. Preferably, extended radiochemical analyses are necessary before a radioactive waste package get licensed for disposal.

One of these assemblies is a beam dump from a former irradiation station for medical treatment, which is a representative object for systematic scientific studies. A complete radiochemical characterisation of its radionuclide inventory was carried out in order to compile a depth and radial radionuclide distribution profile and to evaluate the risks during an intermediate storage of this or similar materials, whereas special attention was paid to extremely long-lived radionuclides. The determination of these species requires previous chemical separation. Single separation procedures for every radio-element had to be developed and applied. Experimental results of these investigations are presented in this report.

The experimentally determined values are compared with theoretical predictions and serve as a base for the improvement of calculation codes and models. Preliminary results of these calculations can be found in [12], an extended version is foreseen for publication in the near future.

Besides the determination of the most hazardous radioisotopes like ${ }^{60} \mathrm{Co}$, it turned out that several exotic longlived radionuclides like ${ }^{26} \mathrm{Al},{ }^{44} \mathrm{Ti}$ or ${ }^{60} \mathrm{Fe}$ are found in con- siderable amounts in this beam dump, making it worth thinking about a preparative separation. If one considers that some of these radionuclides have no other reasonable production route, the "mining of isotopes" from accelerator waste seems to be a prospective new way for exotic isotope production. As an outcome of the represented analytical studies, an international collaboration on the exploitation of accelerator waste for gaining exotic radionuclides for several scientific and technological purposes - called ERAWAST $[13,14]$ - was created, starting with an ESFfunded workshop at PSI in 2006.

\section{Experimental section}

\subsection{Sample description}

The material under investigation was an assembly made from copper and used as a beam dump in the former "BioMedical-Area" (BMA). There, patients were irradiated for cancer treatment with negative pions produced in a beryllium target hit by $590 \mathrm{MeV}$ protons - a so-called PIOTRON. Details of the beam line can be seen in Fig. 1.

From the main beam a fraction of $20 \mu \mathrm{A}$ had been split off with an electrostatic splitter (SPLITTER). By use of two dipole magnets (ABK1 and ABK2) the proton beam was focused onto the pion production target.

This device was in operation for approximately $12 \mathrm{y}$. It was switched off in 1992 and dismantled. The copper beam dump had a diameter of $8 \mathrm{~cm}$ and a length of $37 \mathrm{~cm}$. It was cut into pieces and stored for further investigation in a hotcell. In Fig. 2 a schematic view of the 7 beam dump pieces is shown. From every single piece, samples were taken by drilling from the centre and periphery position, respectively. From piece 3, 3 additional samples were taken in 1,2 and $3 \mathrm{~cm}$ distance from centre in order to determine the radial radionuclide distribution. A drawing of the sample positions can be seen in Fig. 2, whereas Fig. 3 shows a view through the lead glass window of the hotcell after sample taking and before drilling. The piece number is marked with black lines; the piece 3 with the 5 sample taking positions can be seen in the upper part of the picture.

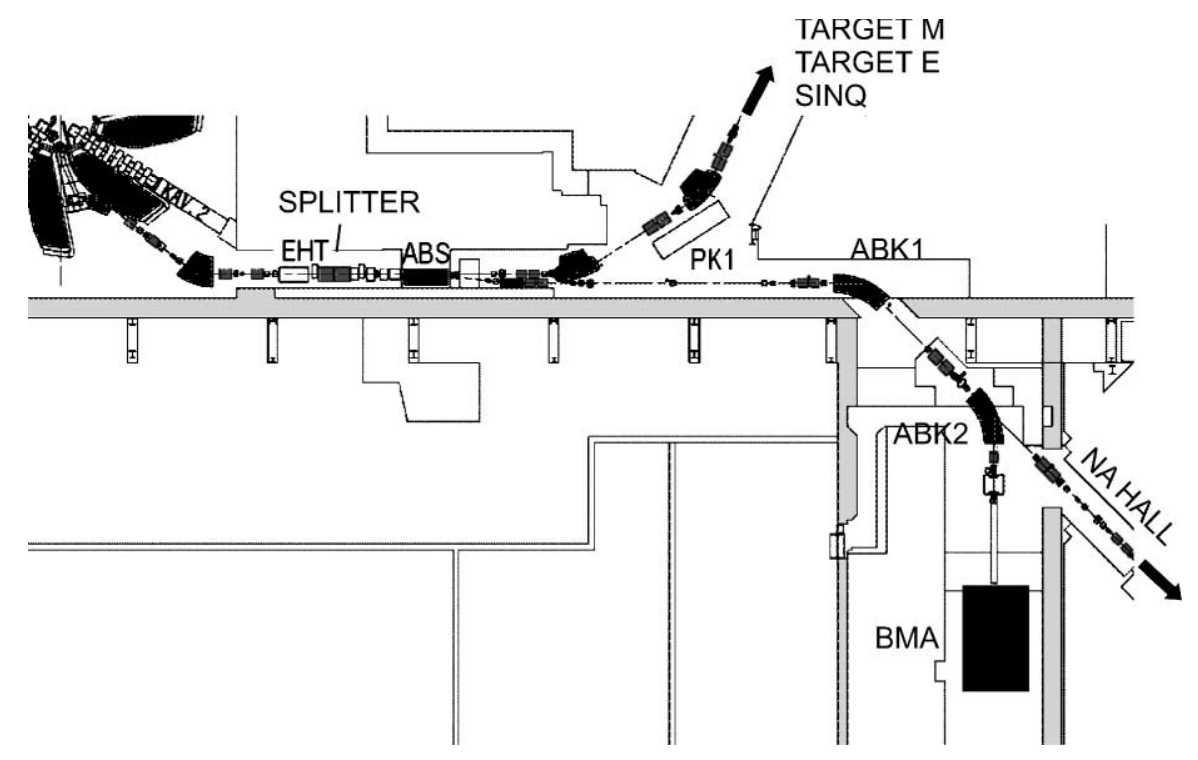

Fig. 1. Schematic drawing of the beam line from the main ring cyclotron to the BMA area (black box). $20 \mu \mathrm{A}$ of the $590 \mathrm{MeV}$ proton beam could be split off and guided onto the pion production target of the BMA facility via the dipole magnets $\mathrm{ABK} 1$ and $\mathrm{ABK} 2$. 


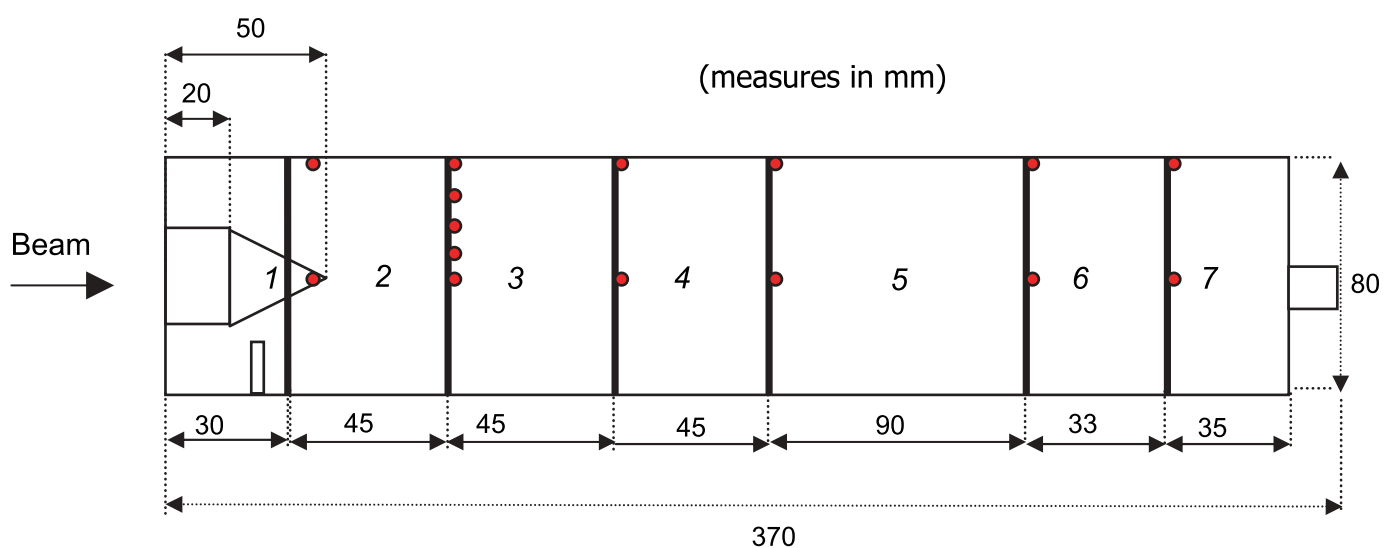

Fig. 2. Detailed schematic view of the $\mathrm{Cu}$ beam dump with the sample taking positions.

\subsection{Selection of radionuclides}

The decision, which radionuclides within such a beam dump assembly have to be studied in detail, has to meet several requirements. Concerning the safety of a final or intermediate disposal, the most hazardous isotopes are characterized by the following criteria:

- The kind of radiation

$\alpha$ - as well as high-energetic $\beta$ - and $\gamma$-emitting radionuclides count as the most hazardous components concerning their damage potential in living tissue. Their allowable limits are essential lower than those for other radionuclides.

- The half-life

Radionuclides with very long half-lives (over 100 years) are to be specially considered concerning their behavior in a final disposal. This task is complicated by the fact that the production rates of long-lived residue nuclides in spallation reactions - in contrast to the nuclear inventory of nuclear fission waste - are not well-known.

- The total amount of activity

Exceeding the legal limits is in no case allowed. Therefore, all radionuclides potentially to exceed the limits have to be determined.

- The chemical properties of the radio-elements

The chemical and physico-chemical behavior of a radioelement, in particular properties like solubility in aqueous media, ion mobility in groundwater, adsorption and desorption behavior on rocks and stones, uptake into the biosphere, volatility, vapor pressure and others, influence the evaluation of its risk potential.
Moreover, if one is interested in extraction of valuable radionuclides from beam dump material for further use, the content of these radio-isotopes should also be determined as accurate as possible in order to avoid unnecessary amounts of low-active "starting material" for the separation procedures.

Taking into account all these criteria, the following conclusions concerning the study of the copper beam dump, were drawn:

1. $\alpha$-emitting radionuclides of considerable amounts are not produced from copper.

2. ${ }^{60} \mathrm{Co}$, with high-energetic $\gamma$-radiation of 1173 and $1332 \mathrm{keV}$, is the dose-rate-determining radionuclide and has to be measured within the samples in any case.

3. Radio-elements with very long half-lives (more than $20 \mathrm{y}$ ), produced directly from copper, have to be determined in all cases where possible, because they may influence the long-term assessment of a final disposal.

4. In some cases, where the nuclear reaction channels show comparatively high production cross sections, also reactions of protons with impurities of the target material have to be considered, whereas impurities lower than $1 \mathrm{ppm}$ are not assumed to give measurable activities of radio-products. (See Table 1: composition of the copper beam dump material). This condition makes the analysis very complex. If lead is considered as the impurity with the highest possible mass number, then we have to expect the production of 48 radionuclides with half-lives more than $20 \mathrm{y}$. A complete analysis of all these radionuclides is, of

Table 1. Elemental composition of the material used for the copper beam dump, taken from certificate (unit: weight in parts per million [ppm]).

\begin{tabular}{lccccccc}
\hline Element & wt [ppm] & Element & wt [ppm] & Element & wt [ppm] & Element & wt [ppm] \\
\hline $\mathrm{Cu}$ & 999769.0 & $\mathrm{Zn}$ & 6.0 & $\mathrm{Na}$ & 1.0 & $\mathrm{Mg}$ & 0.5 \\
$\mathrm{Fe}$ & 60.0 & $\mathrm{Sn}$ & 5.0 & $\mathrm{Cr}$ & 1.0 & $\mathrm{Co}$ & 0.5 \\
$\mathrm{P}$ & 40.0 & $\mathrm{Ni}$ & 4.0 & $\mathrm{Cs}$ & 1.0 & $\mathrm{Li}$ & 0.5 \\
$\mathrm{Cl}$ & 30.0 & $\mathrm{Mo}$ & 3.0 & $\mathrm{Ho}$ & 1.0 & $\mathrm{~B}$ & 0.5 \\
$\mathrm{~S}$ & 15.0 & $\mathrm{Ca}$ & 2.5 & $\mathrm{Si}$ & 1.0 & $\mathrm{~K}$ & 0.5 \\
$\mathrm{Ag}$ & 13.0 & $\mathrm{Ga}$ & 2.0 & $\mathrm{As}$ & 1.0 & $\mathrm{Th}$ & 0.5 \\
$\mathrm{~N}$ & 10.0 & $\mathrm{Hg}$ & 2.0 & $\mathrm{Rb}$ & 1.0 & $\mathrm{U}$ & 0.5 \\
$\mathrm{Al}$ & 10.0 & $\mathrm{~V}$ & 1.5 & $\mathrm{Bi}$ & 1.0 & $\mathrm{Ba}$ & 0.4 \\
$\mathrm{~Pb}$ & 8.0 & $\mathrm{Ti}$ & 1.0 & $\mathrm{Mn}$ & 0.5 & $\mathrm{Eu}$ & 0.2 \\
\hline
\end{tabular}




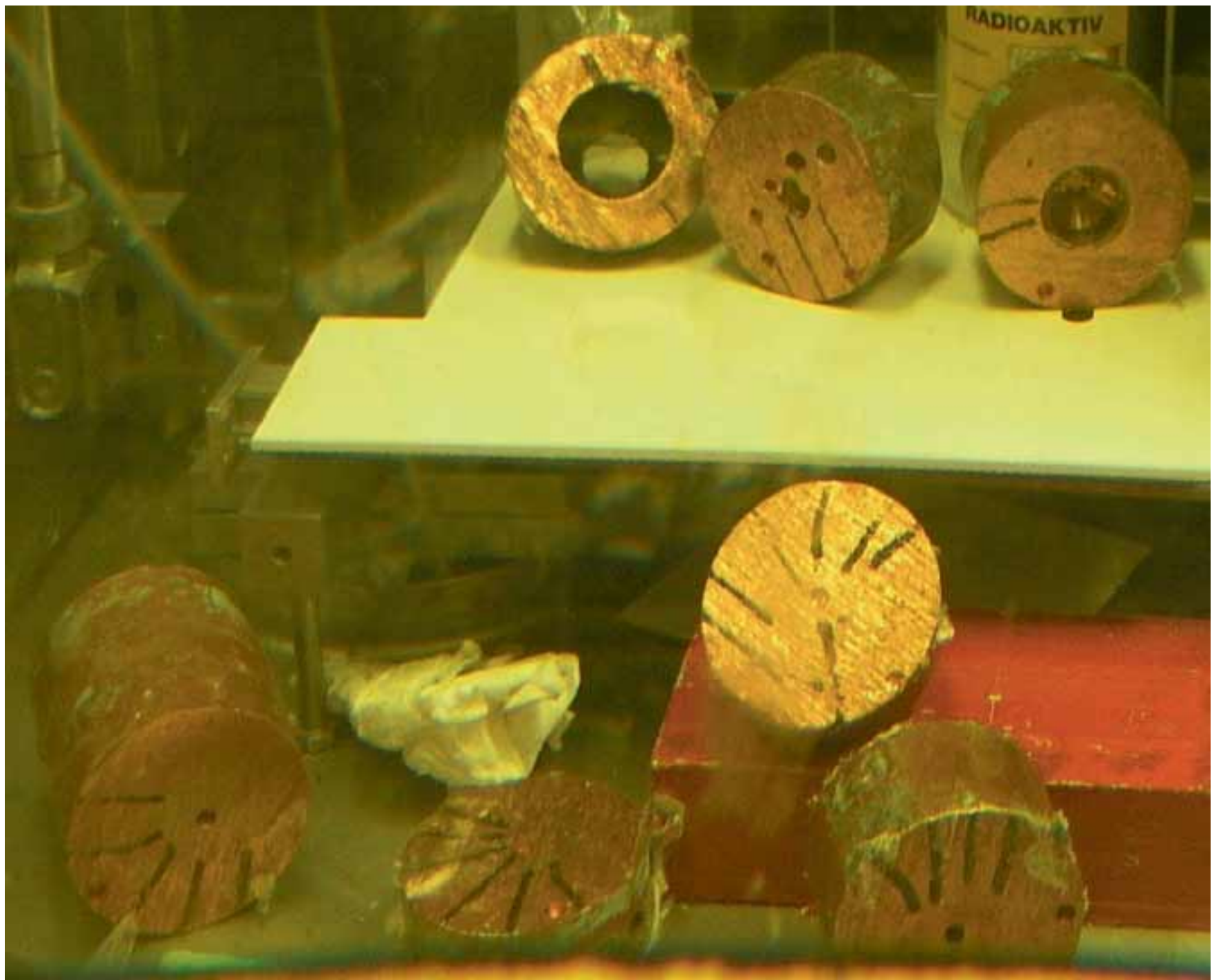

Fig. 3. Photo of the 7 copper pieces through the lead glass window of the hot cell; the number of the respective piece is marked with black lines. On the upper part, the parts 1-3 can be seen; piece 3 shows the 5 sample taking positions for the radial distribution.

course, not possible. Representative examples have to be selected.

Following these requirements, we focused on the following radionuclides:

- ${ }^{60} \mathrm{Co}(5.3 \mathrm{y})$ : high-energetic $\gamma$-emitter, dose-rate relevant,

- ${ }^{60} \mathrm{Fe}\left(1.5 \times 10^{6} \mathrm{y}\right),{ }^{59} \mathrm{Ni}\left(7.6 \times 10^{4} \mathrm{y}\right),{ }^{26} \mathrm{Al}\left(7.17 \times 10^{5} \mathrm{y}\right)$, ${ }^{53} \mathrm{Mn}\left(3.74 \times 10^{6} \mathrm{y}\right)$, very long-lived radionuclides; interesting for scientific purposes,

- ${ }^{55} \mathrm{Fe}(2.7 \mathrm{y})$ : activity comparable with ${ }^{60} \mathrm{Co}$, potentially disturbing radionuclide in a ${ }^{60} \mathrm{Fe}$ sample,

- ${ }^{44} \mathrm{Ti}(63 \mathrm{y})$ : interesting for scientific purposes,

- ${ }^{36} \mathrm{Cl}\left(3.01 \times 10^{5} \mathrm{y}\right)$ : very long-lived radionuclide; high solubility and ionic mobility in aqueous solution,

- ${ }^{42} \mathrm{Ar}$ (39.9 y): example for volatile components,

- ${ }^{63} \mathrm{Ni}$ (100.1 y): high activity, potentially disturbing radionuclide in a ${ }^{59} \mathrm{Ni}$ sample,

- ${ }^{108 m} \mathrm{Ag}$ (418 y): produced from silver by neutron activation (see section "Results and Discussion") as one example for benchmarking the production from impurities.

\subsection{Measurement techniques}

First examination of the samples was done by $\gamma$-measurement without sample destruction using a high purity germanium detector (HPGe, CANBERRA instruments). The determination of the silver isotopes was carried out also by $\gamma$-measurement, but after chemical separation (see Sect. 2.4).

${ }^{55} \mathrm{Fe},{ }^{36} \mathrm{Cl}$ and ${ }^{63} \mathrm{Ni}$ were determined by Liquid Scintillation Counting (LSC) using TriCarb equipment and Ultima Gold LLT (former Packard, now PerkinElmer) as scintillator.

Radionuclides with very long half-lives and/or no measurable radiation cause problems concerning their determination. In many of these cases, counting of atoms instead of decays proved to be the better approach. This can be done by mass spectrometry methods like inductively-coupledplasma-mass-spectrometry (ICP-MS) or accelerator mass spectrometry (AMS). All the long-lived radionuclides reported on here were determined using the AMS facilities at ETH Zürich, Switzerland (6 MV van-de-Graaff EN tan- 
dem accelerator at the PSI/ETH Laboratory of Ion Beam Physics) and at TU Munich, Germany (14 MV MP tandem at the Beschleunigerlabor of LMU and TUM).

\subsection{Chemical separation techniques}

As the first step of all separation procedures, about 1-10 mg of the sample material from every sample taking point were weighed in and a quantitative $\gamma$-measurement of every sample was performed. In all cases, the total activity was dominated by the content of ${ }^{60} \mathrm{Co}$, being at least 50 times higher than any other radionuclide (see Table 2). This high amount of ${ }^{60} \mathrm{Co}$ requires rather high-sophisticated separation techniques, because in some cases, a decontamination factor of up to $10^{6}$ is necessary to get a measurable sample.

Determination of the activity by LSC or $\gamma$-spectrometry following chemical separation demands the chemical yields of the separation procedures. For the ${ }^{55} \mathrm{Fe}$ and ${ }^{63} \mathrm{Ni}$ measurements, this was done by ICP-OES; the yield of chloride was determined gravimetrically; for the chemically separated silver samples, these values were determined by Atomic Absorption Spectrometry (AAS). The chemical yields between these 3 radionuclides varied between 60 and 90\%. Performance of AMS does not require the knowledge of chemical yields, because an isotopic ratio is determined. However, for this technique, additionally a good separation of the isobaric elements is necessary because they can interfere with the isotope under study. In general, the content of isobaric isotopes has to be at least a factor $10^{2}$ lower than the isotope for a proper AMS measurement. In many cases, much better decontamination factors could be obtained, as is for instance described in [14] for ${ }^{60} \mathrm{Fe}$, where a decontamination from ${ }^{60} \mathrm{Co}$ of $10^{8}$ was reached.

\section{${ }^{36} \mathrm{Cl}$}

After completing the $\gamma$-measurement, the sample was transferred into a tight three-neck flask. $10 \mathrm{mg}$ of isotopic chlorine carrier were added, and the copper was dissolved in $7 \mathrm{M}$
$\mathrm{HNO}_{3}$ under heating, and the obtained solution was evaporated to dryness. A nitrogen stream was used to transport the chlorine trough a connection tube into an absorption vessel containing $\mathrm{AgNO}_{3}$ solution. The precipitate of $\mathrm{AgCl}$ was filtered and dissolved in ammonia solution. For the separation of stable ${ }^{36} \mathrm{~S}$ - the isobar of ${ }^{36} \mathrm{Cl}$ - an additional precipitation step with $\mathrm{Ba}\left(\mathrm{NO}_{3}\right)_{2}$ as reagent was introduced in order to remove sulphur in form of non-soluble $\mathrm{BaSO}_{4}$. Afterwards, $\mathrm{AgCl}$ was re-crystallized, washed with bi-distilled water and dried at $80^{\circ} \mathrm{C}$ to get a sample ready for AMS use.

The dry residue of every sample in the dissolution vessel was completely dissolved in $10 \mathrm{~mL} 1 \mathrm{M} \mathrm{HNO}_{3}$. Aliquots of these "starting solutions" (SS) were used for the following single element separations.

\section{${ }^{55} \mathrm{Fe} /{ }^{60} \mathrm{Fe}$}

To an aliquot of SS, $5 \mathrm{mg}$ of isotopic iron carrier were added, the solution was evaporated to dryness, and the residue was re-dissolved in $7 \mathrm{M} \mathrm{HCl}$. Diisopropylether was used as organic reagent for liquid-liquid extraction, which allows to separate iron selectively with a chemical yield of nearly $100 \%$. Back-extraction was carried out using $0.1 \mathrm{M} \mathrm{HCl}$. The procedure was repeated twice in order to get rid off ${ }^{60} \mathrm{Co}$ traces as well as the ${ }^{60} \mathrm{Ni}$ contamination which can - as an isobar of ${ }^{60} \mathrm{Fe}$ - interfere the AMS measurement of this radionuclide.

For the ${ }^{55} \mathrm{Fe}$ determination, aliquots from these final solutions were mixed with the organic scintillator solution (Ultima Gold LLT) in a ratio of $1: 9$ and counted via LSC.

For AMS measurement aimed to determine ${ }^{60} \mathrm{Fe}$, the iron was precipitated with ammonia solution; the precipitate was washed twice with bi-distilled $\mathrm{H}_{2} \mathrm{O}$ and dried in a cabinet desiccator.

\section{${ }^{59 / 63} \mathrm{Ni}$}

An aliquot of SS was spiked with $5 \mathrm{mg}$ stable Ni. To this solution, $10 \mathrm{~mL}$ of half-concentrated ammonia solution and $2 \mathrm{~mL} \mathrm{5 \%} \mathrm{dimethylglyoxime} \mathrm{(DMG)} \mathrm{solution} \mathrm{in} \mathrm{ethanol}$

Table 2. Values for the activity obtained by $\gamma$-measurement $\left({ }^{44} \mathrm{Ti},{ }^{22} \mathrm{Na},{ }^{42} \mathrm{~K},{ }^{108 \mathrm{~m}} \mathrm{Ag},{ }^{60} \mathrm{Co}\right)$ and $\mathrm{LSC}\left({ }^{63} \mathrm{Ni},{ }^{55} \mathrm{Fe}\right)$; sample description X.Y: X $\rightarrow$ number of beam dump piece; Y: 1 - central position, 2 - peripheral position; Exception: beam dump piece 3. Y: $1-$ central position, $2-1 \mathrm{~cm}$ distance from centre, $3-2 \mathrm{~cm}$ distance from centre, $4-3 \mathrm{~cm}$ distance from centre, 5 - peripheral position (Fig. 2). Dates of the measurements for the short-lived isotopes: ${ }^{55} \mathrm{Fe},{ }^{63} \mathrm{Ni}: 12 / 05 ;{ }^{44} \mathrm{Ti},{ }^{60} \mathrm{Co}: 01 / 06,{ }^{108 \mathrm{~m}} \mathrm{Ag},{ }^{65} \mathrm{Zn},{ }^{42} \mathrm{Ar}: 12 / 00$.

\begin{tabular}{|c|c|c|c|c|c|c|c|c|c|}
\hline $\begin{array}{l}\text { Sample } \\
\text { X.Y }\end{array}$ & $\begin{array}{c}{ }^{44} \mathrm{Ti} \\
{[\mathrm{kBq} / \mathrm{g}]}\end{array}$ & $\begin{array}{c}{ }^{22} \mathrm{Na} \\
{[\mathrm{kBq} / \mathrm{g}]}\end{array}$ & $\begin{array}{c}{ }^{63} \mathrm{Ni} \\
{[\mathrm{kBq} / \mathrm{g}]}\end{array}$ & $\begin{array}{c}{ }^{55} \mathrm{Fe} \\
{[\mathrm{kBq} / \mathrm{g}]}\end{array}$ & $\begin{array}{c}{ }^{42} \mathrm{Ar} \\
{[\mathrm{kBq} / \mathrm{g}]}\end{array}$ & $\begin{array}{l}{ }^{108 \mathrm{~m}} \mathrm{Ag} \\
{[\mathrm{Bq} / \mathrm{g}]}\end{array}$ & $\begin{array}{c}{ }^{60} \mathrm{Co} \\
{[\mathrm{kBq} / \mathrm{g}]}\end{array}$ & $\begin{array}{c}{ }^{65} \mathrm{Zn} \\
{[\mathrm{kBq} / \mathrm{g}]}\end{array}$ & $\begin{array}{l}\text { Distance from beam } \\
\text { entrance }[\mathrm{mm}]\end{array}$ \\
\hline 2.1 & $1620(160)$ & 115(11) & $34200(3400)$ & $42400(4200)$ & $367(38)$ & $63(6)$ & $500000(5000)$ & $240(24)$ & 0 \\
\hline 2.2 & $0.20(2)$ & & 218(22) & 109(11) & - & $1.4(1)$ & 112(11) & & \\
\hline 3.1 & 741(74) & $42(4)$ & $36600(3700)$ & 44 100(4400) & $173(17)$ & $37(4)$ & $38000(3800)$ & $50(5)$ & 20 \\
\hline 3.2 & $19(2)$ & $2.0(2)$ & 2010(200) & $2560(260)$ & $12(1)$ & $9.2(1)$ & $2700(270)$ & & \\
\hline 3.3 & $1.5(2)$ & - & $1110(110)$ & $1550(160)$ & $5.7(6)$ & $9.2(1)$ & $1240(120)$ & & \\
\hline 3.4 & $0.6(1)$ & - & $1840(180)$ & 257(26) & - & $1.7(2)$ & 663(66) & $16(2)$ & \\
\hline 3.5 & $0.40(4)$ & - & 706(71) & 155(16) & - & $1.0(1)$ & 439(44) & 11(1) & \\
\hline 4.1 & $778(78)$ & $32(3)$ & $16800(1700)$ & $26600(2700)$ & - & $28(3)$ & $47300(4700)$ & & 60 \\
\hline 4.2 & - & - & 799(80) & $132(13)$ & - & $1.3(1)$ & $506(51)$ & & \\
\hline 5.1 & $95(10)$ & - & $5770(580)$ & $115200(1160)$ & - & 13(1) & $10100(101)$ & & 105 \\
\hline 5.2 & - & - & $546(55)$ & $158(16)$ & - & $1.8(2)$ & $415(42)$ & $13(1)$ & \\
\hline 6.1 & - & - & 1010(100) & 288(29) & - & $3.9(4)$ & $459(46)$ & $1.8(2)$ & 203 \\
\hline 6.2 & - & - & $233(23)$ & $128(13)$ & - & $0.9(1)$ & $170(17)$ & $7.9(8)$ & \\
\hline 7.1 & - & - & $170(17)$ & $351(35)$ & - & $1.3(1)$ & $147(15)$ & $6.0(6)$ & 236 \\
\hline 7.2 & - & - & 119(12) & $234(23)$ & - & $0.9(1)$ & $91(9)$ & & \\
\hline
\end{tabular}


were added. Under these conditions, a pink-coloured NiDMG complex is formed as insoluble precipitate. The precipitate was washed twice with bi-distilled $\mathrm{H}_{2} \mathrm{O}$.

For determination of ${ }^{63} \mathrm{Ni}$, the precipitate was dissolved in $3 \mathrm{M} \mathrm{HNO}_{3}$, mixed with the scintillator solution in a ratio $1: 9$ and measured via LSC.

AMS samples require Ni to be present in the form of $\mathrm{NiO}$. The Ni-DMG-complex itself can be glowed to the oxide, but due to its high volatility, essential losses of material were observed, which causes additionally a high contamination risk of the muffle furnace. Therefore, the method was slightly modified in the following way: The complex was dissolved in $3 \mathrm{M} \mathrm{HNO}_{3}$, and $\mathrm{Ni}$ was precipitated as hydroxide with diluted $\mathrm{NaOH}$ solution. The $\mathrm{Ni}(\mathrm{OH})_{2}$ can easily be glowed to the oxide at $800^{\circ} \mathrm{C}$ without any losses.

\section{${ }^{26} \mathrm{Al}$}

$2 \mathrm{mg}$ of carrier were added and $\mathrm{Al}$ was separated by precipitating the hydroxide with ammonia solution. Under these conditions, ${ }^{60} \mathrm{Co}$ as well as the macro-amount of the target material, copper, remains in solution as ammonia complex. Re-crystallisation of the precipitate by alternately adding acid and ammonia solution purifies the hydroxide. A final purification was achieved by dissolving the hydroxide in $0.1 \mathrm{M} \mathrm{HNO}_{3}$ solution and adsorption onto a cation exchange column (Dowex 50 $\times 8$ 150-200 mesh). Elution of $\mathrm{Al}$ was performed using $4 \mathrm{M} \mathrm{HCl}$ as eluent. The hydroxide was precipitated again and annealed at $900{ }^{\circ} \mathrm{C}$ to obtain the oxide, the chemical form required for the AMS measurement.

\section{${ }^{53} \mathrm{Mn}$}

After adding $5 \mathrm{mg}$ carrier, $\mathrm{Mn}$ was precipitated as $\mathrm{MnO}(\mathrm{OH})_{2}$ by using a mixture of $\mathrm{NH}_{4} \mathrm{OH}$ and $\mathrm{H}_{2} \mathrm{O}_{2}$. After washing with bi-distilled water manganese dioxide $-\mathrm{a}$ form suitable for AMS - can be obtained by drying at $80^{\circ} \mathrm{C}$.

\section{${ }^{108 m} \mathrm{Ag}$}

The separation of Ag follows classical procedures via adding $4 \mathrm{mg}$ carrier and precipitation with $\mathrm{HCl}$. The precipitate is purified similar to the chlorine samples. The amount of ${ }^{108 \mathrm{~m}} \mathrm{Ag}$ was determined by $\gamma$-spectrometry.

\section{Results and discussion}

\subsection{General}

In the Tables 2 and 3 the results of the LSC and $\gamma$-measurements (Table 2) as well as the AMS measurements for the long-lived radionuclides (Table 3 ) are summarized.

From these values, a radial and length distribution for selected radionuclides within the copper beam dump was calculated. We used the kriging $[15,16]$ interpolation method to visualize the obtained data in a two dimensional contour plot. It is a best linear unbiased estimator for optimal prediction of unknown values from data observed at known locations. In order get a better comparison between the radionuclides, the values were normalized to relative units by setting the total values as 100 , respectively. From Fig. 4 it can be clearly seen, that the distribution of the
Table 3. Results of the AMS measurements; sample description similar to that in Table 2.

\begin{tabular}{lccccc}
\hline $\begin{array}{l}\text { Sample } \\
X . Y\end{array}$ & $\begin{array}{c}{ }^{36} \mathrm{Cl} \\
{[\mathrm{Bq} / \mathrm{g}]}\end{array}$ & $\begin{array}{c}{ }^{26} \mathrm{Al} \\
{[\mathrm{Bq} / \mathrm{g}]}\end{array}$ & $\begin{array}{c}{ }^{59} \mathrm{Ni} \\
{[\mathrm{Bq} / \mathrm{g}]}\end{array}$ & $\begin{array}{c}{ }^{53} \mathrm{Mn} \\
{[\mathrm{Bq} / \mathrm{g}]}\end{array}$ & $\begin{array}{c}{ }^{60} \mathrm{Fe} \\
{[\mathrm{Bq} / \mathrm{g}]}\end{array}$ \\
\hline 2.1 & $1280(130)$ & $140(14)$ & $127000(12700)$ & $6900(690)$ & 84.7 \\
2.2 & $0.30(3)$ & $0.010(1)$ & $129(13)$ & $0.6(1)$ & - \\
3.1 & $279(28)$ & $56(6)$ & $125000(12500)$ & $4310(431)$ & 58.5 \\
3.2 & $0.19(2)$ & $1.1(1)$ & $6620(660)$ & $112(11)$ & 3.3 \\
3.3 & $0.020(2)$ & $0.20(2)$ & $2620(260)$ & $18(2)$ & 1.9 \\
3.4 & $0.01(1)$ & $0.030(3)$ & $759(76)$ & $5.6(6)$ & 0.5 \\
3.5 & $0.35(3)$ & $0.010(1)$ & $466(47)$ & $4.3(4)$ & 0.5 \\
4.1 & $173(17)$ & $41(4)$ & - & $3600(400)$ & $52(5)$ \\
4.2 & $0.24(2)$ & $0.010(1)$ & - & $2.1(2)$ & - \\
5.1 & $79(8)$ & $3.0(3)$ & $25700(2600)$ & $998(100)$ & $20(2)$ \\
5.2 & $0.27(3)$ & $0.010(1)$ & $422(42)$ & $2.0(2)$ & - \\
6.1 & $0.13(1)$ & $0.0120(1)$ & $6940(700)$ & $10(1)$ & $0.70(7)$ \\
6.2 & $0.10(1)$ & $0.00190(2)$ & - & $0.60(6)$ & - \\
7.1 & $0.10(1)$ & $0.0050(5)$ & $1.0(1)$ & $1.4(1)$ & $0.70(7)$ \\
7.2 & $0.040(4)$ & $0.00130(1)$ & - & $0.50(5)$ & - \\
\hline
\end{tabular}

Table 4. Approximate $Q$-values for the production of nuclides from ${ }^{63} \mathrm{Cu}$ and ${ }^{65} \mathrm{Cu}$. The $Q$-values have been calculated using the Weizsäcker mass formula [17].

\begin{tabular}{|c|c|c|c|c|c|}
\hline${ }^{63} \mathrm{Cu}$ & Nuclide & $\begin{array}{c}Q \text {-Value } \\
{[\mathrm{MeV}]}\end{array}$ & ${ }^{65} \mathrm{Cu}$ & Nuclide & $\begin{array}{c}Q \text {-Value } \\
{[\mathrm{MeV}]}\end{array}$ \\
\hline & ${ }^{26} \mathrm{Al}$ & -340.5 & & ${ }^{26} \mathrm{Al}$ & -359.4 \\
\hline & ${ }^{44} \mathrm{Ti}$ & -175.7 & & ${ }^{44} \mathrm{Ti}$ & -194.5 \\
\hline & ${ }^{53} \mathrm{Mn}$ & -89.7 & & ${ }^{53} \mathrm{Mn}$ & -108.5 \\
\hline & ${ }^{59} \mathrm{Ni}$ & -38.2 & & ${ }^{59} \mathrm{Ni}$ & -57.1 \\
\hline & ${ }^{60} \mathrm{Fe}$ & -24.9 & & ${ }^{60} \mathrm{Fe}$ & -43.7 \\
\hline
\end{tabular}

radionuclides depicted depends on their mass number. For isotopes with mass numbers quite different from the mass number of the target, like for instance ${ }^{26} \mathrm{Al}$ (produced by spallation reactions), we observe a concentration of activity around the beam entrance. For nuclides near the target mass (example: ${ }^{108 \mathrm{~m}} \mathrm{Ag}$, produced by neutron-induced nuclear reactions from impurities of $\mathrm{Ag} ;{ }^{65} \mathrm{Zn}$ produced by proton-induced nuclear reaction), the residue nuclei are spread more or less over the entire beam dump. This radionuclide distribution is caused by the type and the threshold (selected $Q$-values depicted in Table 4) of the corresponding nuclear reaction and therefore corresponds to the energy loss of the proton beam. In Fig. 5, this energy loss is depicted for copper as target material; Fig. 6 shows the corresponding intensity losses of the protons in beam direction and radially. The influence of the nuclear reaction types and the corresponding thresholds are discussed in detail in [12].

Direct correlations of the residue nuclide distribution to the proton spectrum can be found in cases where pure proton-induced reactions can be expected as dominant reaction type. One example is the production and distribution of ${ }^{26} \mathrm{Al}$, which is mainly formed in the reaction ${ }^{63 / 65} \mathrm{Cu}(p, 17 p, 20 / 22 n){ }^{26} \mathrm{Al}$. According to Table 4, the threshold for this reaction is about $340-360 \mathrm{MeV}$. In a depth of the beam dump of more than $120 \mathrm{~mm}$ we do not find protons with such high energies (see Fig. 5), and, corresponding to that and visible in Fig. $4,{ }^{26} \mathrm{Al}$ was not detected in considerable amounts in regions deeper than 


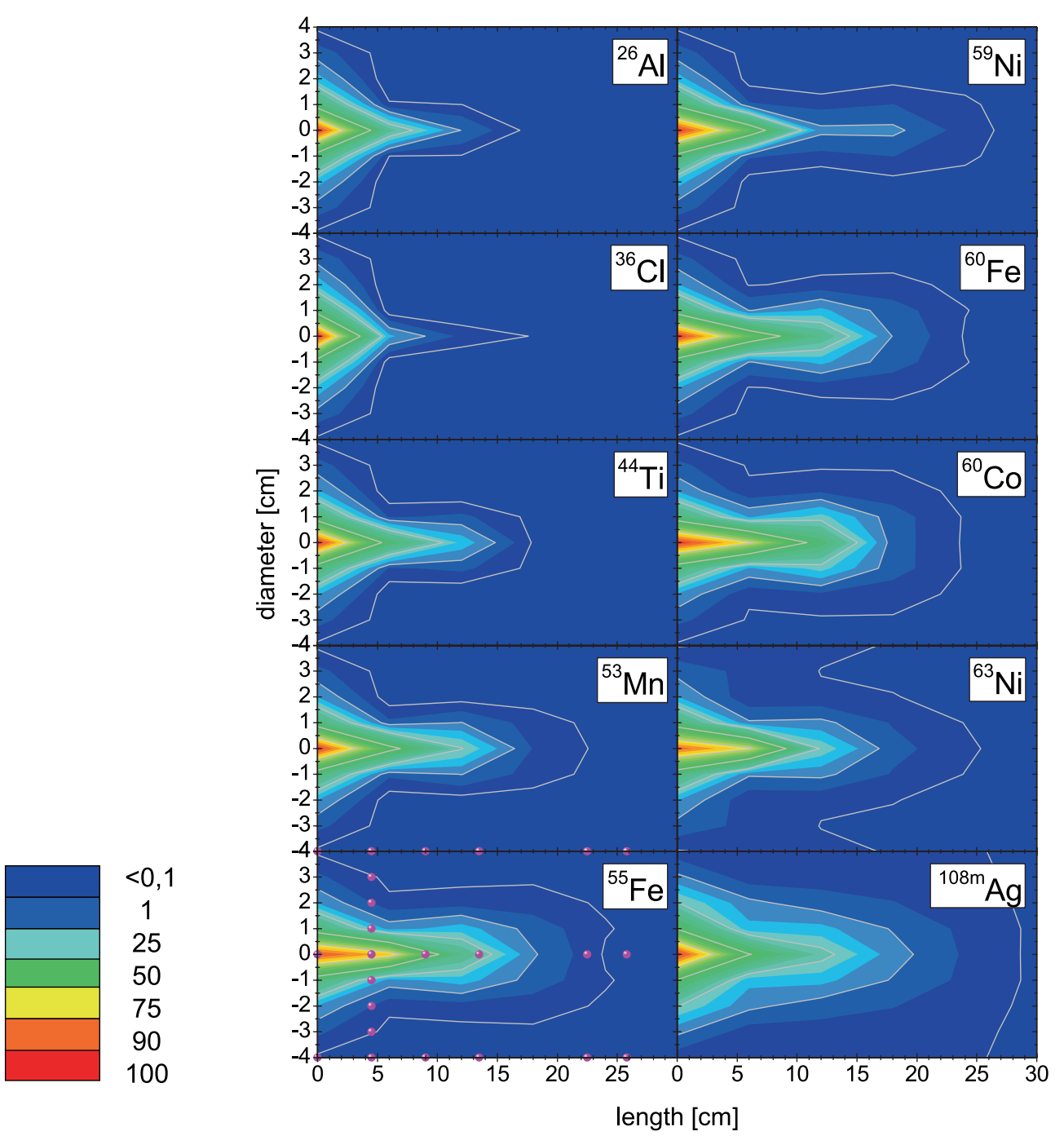

Fig. 4. Spatial distribution of selected radionuclides within the copper beam dump, values normalized to the maximum values, respectively.

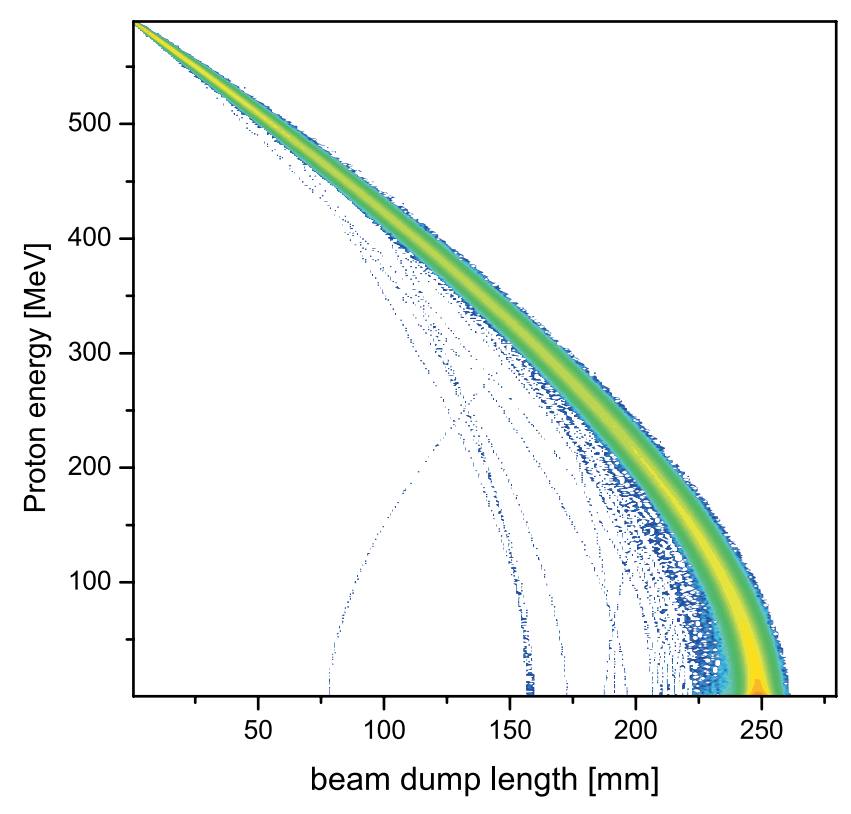

$120 \mathrm{~mm}$. The distribution of ${ }^{26} \mathrm{Al}$ is also correlated to the intensity distribution of the proton beam depicted in Fig. 6, e.g. in a radius of $10 \mathrm{~mm}$ around the centre we rel. Intensity

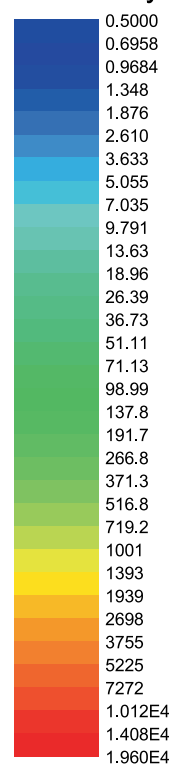

Fig. 5. Dependence of the proton energy and proton beam intensity on the depth of penetration. can found approximately $80 \%$ of the residues. Residues which are mainly produced by neutron-induced reactions, like for instance ${ }^{108 \mathrm{~m}} \mathrm{Ag}$, show a distribution over the en- 


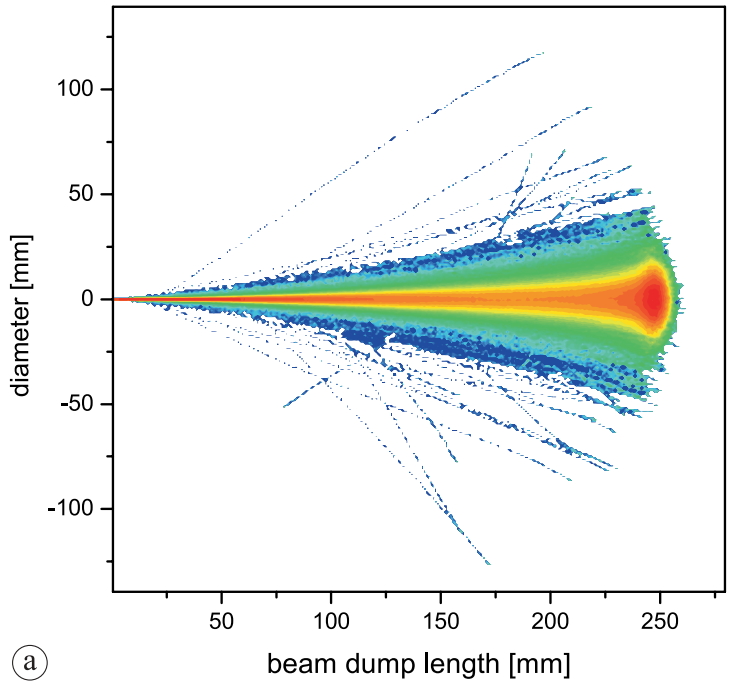

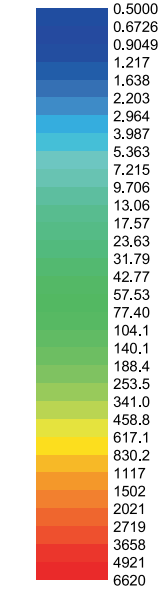

rel. intensity

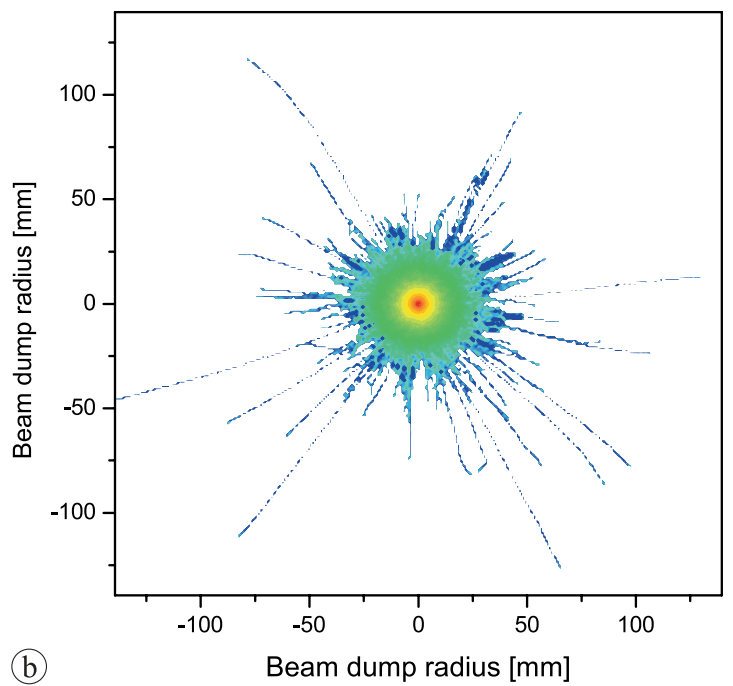

Fig. 6. Distribution of the proton intensity within the beam dump: (a) distribution in beam direction; (b) radial distribution at beam entrance.

tire beam dump (Fig. 4), corresponding to the neutron distribution.

Not in any case, the radionuclide distribution can be explained by such simplified phenomenological examination. A more detailed discussion of the influencing parameters like nuclear reaction types and the corresponding reaction thresholds as well as a comparison of the experimental results with theoretical predictions obtained by use of several model calculations is given in [12].

\subsection{Conclusions and further work}

\section{Safety aspects}

An essential component in the documentation of nuclear waste packages to be stored in a repository is the declaration of the complete inventory, whereas radionuclides with half-lives of more than $60 \mathrm{~d}$ count as safety-relevant. Table 5 shows the declaration limits as well as the ZAK-values for the radionuclides studied in this report.

As the values in Table 5 show, all declaration limits were exceeded, this means that all these radionuclides have to be declared in the documentation for repository, either by measuring or a reasonable and reliable estimation by calculation. On the other hand, all central values on sample 2, which are the highest ones, lie below the ZAK values. Based on this numbers, licensing for final disposal for this package can be expected without problems. This complete radiochemical characterization of such a accelerator component serves as an example for future evaluation of accelerator waste and is the basis for further developments in the management of similar packages.

\section{Preparative separation for scientific purposes}

The separation of carrier-free radioisotopes from several hundred grams or even kilograms of target material represents a big challenge to the radiochemist. Therefore, the objective should be to minimize the amount of copper contained in the sample by working only with the most activated parts. The data obtained in this work are the basis for the further activities within the ERAWAST project. An estimation of the expected activities (or amount of atoms) of selected isotopes that can be obtained from the studied Cu-beamdump was performed in order to get an overview on possible scientific experiments that can be performed using these nuclides: ${ }^{44} \mathrm{Ti}: 100 \mathrm{MBq}\left(10^{18}\right.$ atoms), ${ }^{53} \mathrm{Mn}: 500 \mathrm{kBq}\left(10^{19}\right.$ atoms $),{ }^{26} \mathrm{Al}: 7 \mathrm{kBq}\left(10^{17}\right.$ atoms $),{ }^{60} \mathrm{Fe}$ : $50 \mathrm{kBq}\left(10^{18}\right.$ atoms $),{ }^{59} \mathrm{Ni}: 8 \mathrm{MBq}\left(10^{19}\right.$ atoms $)$. This amount of material will allow nuclear astrophysics experiments like neutron capture reaction studies on ${ }^{60} \mathrm{Fe}$, development of radioactive beams with ${ }^{26} \mathrm{Al}$ as well as the creation of a radionuclide generator ${ }^{44} \mathrm{Ti} /{ }^{44} \mathrm{Sc}$ for radiopharmaceutical purposes. A detailed description of the working program of ERAWAST can be found on the webpage [13]. In preparation of this project, the beam dump was drilled out with a diameter of $2 \mathrm{~cm}$ and a depth of $18 \mathrm{~cm}$ from the beam entrance. About $500 \mathrm{~g}$ of copper ships were obtained con-

Table 5. Declaration limits and ZAK values for sample 2.1.

\begin{tabular}{|c|c|c|c|c|c|c|c|}
\hline Nuclide & $\begin{array}{c}\mathrm{DL} \\
{[\mathrm{Bq} / \mathrm{g}]}\end{array}$ & $\begin{array}{c}\mathrm{ZAK} \\
{[\mathrm{Bq} / \mathrm{g}]}\end{array}$ & $\begin{array}{c}\text { Sample } 2.1 \\
{[\mathrm{~Bq} / \mathrm{g}]}\end{array}$ & Nuclide & $\begin{array}{c}\mathrm{DL} \\
{[\mathrm{Bq} / \mathrm{g}]}\end{array}$ & $\begin{array}{c}\text { ZAK } \\
{[\mathrm{Bq} / \mathrm{g}]}\end{array}$ & $\begin{array}{c}\text { Sample } 2.1 \\
{[\mathrm{~Bq} / \mathrm{g}]}\end{array}$ \\
\hline${ }^{22} \mathrm{Na}$ & $3.0 \times 10^{3}$ & $4.5 \times 10^{7}$ & $1.1 \times 10^{5}$ & ${ }^{55} \mathrm{Fe}$ & $7.0 \times 10^{4}$ & $>10^{10}$ & $4.2 \times 10^{7}$ \\
\hline${ }^{26} \mathrm{Al}$ & 2.0 & $6.6 \times 10^{7}$ & $1.4 \times 10^{2}$ & ${ }^{59} \mathrm{Ni}$ & $2.0 \times 10^{2}$ & $3.3 \times 10^{7}$ & $1.3 \times 10^{5}$ \\
\hline${ }^{36} \mathrm{Cl}$ & $1.0 \times 10^{1}$ & $9.6 \times 10^{5}$ & $1.3 \times 10^{3}$ & ${ }^{60} \mathrm{Co}$ & $1.0 \times 10^{2}$ & $>10^{10}$ & $5.9 \times 10^{7}$ \\
\hline${ }^{42} \mathrm{Ar}$ & $1.0 \times 10^{3}$ & $6.0 \times 10^{5}$ & $3.7 \times 10^{5}$ & ${ }^{60} \mathrm{Fe}$ & 0.3 & $2.8 \times 10^{4}$ & $8.5 \times 10^{1}$ \\
\hline${ }^{44} \mathrm{Ti}$ & $1.0 \times 10^{3}$ & $>10^{10}$ & $1.6 \times 10^{6}$ & ${ }^{63} \mathrm{Ni}$ & $5.0 \times 10^{4}$ & $3.1 \times 10^{9}$ & $3.4 \times 10^{7}$ \\
\hline${ }^{53} \mathrm{Mn}$ & $3.0 \times 10^{2}$ & $5.3 \times 10^{7}$ & $6.9 \times 10^{3}$ & ${ }^{65} \mathrm{Zn}$ & $3.0 \times 10^{3}$ & $>10^{10}$ & $2.4 \times 10^{5}$ \\
\hline
\end{tabular}


taining about $80 \%$ of the activity, which are now ready for chemical separation.

\section{References}

1. http://neutrons.ornl.gov/aboutsns/aboutsns.shtml.

2. http://asq.web.psi.ch/.

3. http://ganinfo.in2p3.fr/research/developments/spiral2/.

4. http://www.cyc.ucl.ac.be/.

5. http://www.ganil.fr/eurisol/.

6. Rubbia, C., Rubio, J. A., Buono, S., Carminati, F., Fietier, N., Galvez, J., Geles, C., Kadi, Y., Klapisch, R., Mandrillon, P., Revol, J. P., Roche, Ch.: Conceptual design of a fast neutron operated high power energy amplifier. CERN/AT/95-44(ET) (1995).

7. Castro, J. R., Petti, P. L., Blakely, E. A., Daftari, I. K.: Particle radiation therapy. In: Textbook of Radiation Oncology. (Leibel, S. A., Phillips, T. L., eds.) Saunders/Elsevier, Philadelphia, PA/ Amsterdam (2004), pp. 1547-1568.

8. Phelps, M. E., Hoffman, E. J., Mullani, N. A., Ter-Pogossian, M. M.: Application of annihilation coincidence detection to transaxial reconstruction tomography. J. Nucl. Med. 16(3), 210 (1975).
9. HINDAS Final Scientific Report, FIS5-00150.

10. Hugi, M., Teichmann, S.: Zulässige Aktivitätskozentrationen und Deklarationslimiten für radioaktive Abfälle des PSI West (Beschleunigerareal). NAGRA Report AN 99-150, Juni (1999).

11. Atchison, F., Teichmann, S.: Realisierung des Verfahrens zur Klassifizierung und Charakterisierung der radioaktiven Abfälle des PSI West: Repräsentative Materialien und Bestrahlungsspektren 590-MeV Areal. PSI AN-96-01-27 (2001).

12. Wohlmuther, M.: Proceedings of ACCAPP2007. AIP Press (2007), p. 259.

13. http://lch.web.psi.ch/radwaste/workshop/index.html.

14. Schumann, D., Neuhausen, J.: Accelerator waste as a source for exotic radionuclides. J. Phys. G Nucl. Part. Phys. 35, 014046 (2008).

15. Krige, D. G.: A statistical approach to some basic mine valuations problems on the witwatersrand. J. Chem. Metal. Mining Soc. S. Africa 52, 119 (1951).

16. Sei-Ichiro, S., Fumihiro, A., Masaru, Z.: Approximate structural optimization using kriging method and digital modeling technique considering noise in sampling data. Comput. Struct. 86, 1477 (2008).

17. Weizsäcker, C. F.: Z. Phys. 96, 431 (1935). 